\title{
Three different clinical faces of the same histopathological entity: hair follicle nevus, trichofolliculoma and accessory tragus*
}

\author{
Yasemin Yuyucu Karabulut ${ }^{1}$ \\ Hac1 Halil Karabulut ${ }^{3}$
}

\author{
Engin Şenel ${ }^{2}$ \\ Yasemin Dölek ${ }^{4}$
}

DOI: http:/ / dx.doi.org/10.1590/abd1806-4841.20153785

\begin{abstract}
BACKGROUND: Hair follicle nevus is a rare, congenital hamartoma with follicular differentiation characterized histologically by numerous, tiny, mature hair follicles. Trichofolliculoma, the histopathological features of which are quite similar to those of hair follicle nevus, is also a hamartoma that differs from hair follicle. Accessory tragus is a relatively common, benign congenital abnormality of the external ear with an incidence rate of 1 to 10 per 1,000 live births.

ОвјестіVE: This study seeks to assess the discriminatory value of currently available, histological criteria in the differential diagnosis of hair follicle nevus, accessory tragi and trichofolliculoma.

MetHods: Twenty-one patients comprising 9 cases of hair follicle nevus, 8 accessory tragi patients and 4 trichofolliculoma cases, were recruited to perform the study.

REsults: There were 10 males and 11 females in the study group. No significant difference was observed between the three study groups in terms of age, gender or histopathological parameters such as density of hair follicles, subcutaneous fat score and presence of connective tissue framework. Cartilaginous component was seen in 8 cases that were diagnosed as accessory tragi, while central cyst and radiating hair follicles were seen in 4 cases which were diagnosed as trichofolliculoma.

CONCLUSION: The results of our study showed that diagnostic discrimination of these diseases could be made only with the clinicopathologic correlation because of their clinical and histopathological similarities.
\end{abstract}

Keywords: Hair follicle; Nevus; Pathology

\section{INTRODUCTION}

Hair follicle nevus is a rare, congenital hamartoma with follicular differentiation characterized histologically by numerous tiny mature hair follicles. ${ }^{1-3}$ Trichofolliculoma, the histopathological features of which are quite similar to those of hair follicle nevus, is also a hamartoma that differs from hair follicle. ${ }^{4}$ Accessory tragus is a relatively common, benign, congenital abnormality of the external ear with an incidence rate of 1 to 10 per 1,000 live births. ${ }^{5-7}$ The disorder is typically a

unilateral and solitary pedunculated or sessile, skincolored papule located in the preauricular region, but it can be multiple or bilateral. ${ }^{8,9}$ Histological examination reveals numerous, tiny, mature hair follicles and prominent connective tissue with or without a cartilaginous component. ${ }^{10,11}$ In the past, the term "hair follicle nevus" was often used instead of trichofolliculoma and accessory tragi. . $^{12-14}$

The relationship of these three conditions inspired us to investigate their histopathological features and similarities across the lesions.

Received on 21.06.2014.

Approved by the Advisory Board and accepted for publication on 04.09.2014.

Work performed at the Hitit University Faculty of Medicine, Department of Dermatology - Çorum, Turkey.

Financial Support: None.

Conflict of Interest: None.

Mersin University - Mersin, Turkey.

Hitit University - Corum, Turkey.

Vizyon Eye Hospital - Mersin, Turkey.

Çankiri State Hospital - Çankiri, Turkey.

(C2015 by Anais Brasileiros de Dermatologia 


\section{METHODS}

This study included a total of 21 patients who were diagnosed with hair follicle nevus (9), accessory tragus (8) and trichofolliculoma (4), between 20112013 in our hospital. Demographic and clinical data of the patients were retrospectively reviewed. Pathology slides were evaluated histologically regardless of the clinical diagnosis and histological assessment was performed in a blinded manner, while the density of hair follicles (graded as 3-6 hair follicles: +, 7-11 hair follicles :,$++>11$ hair follicles: +++$)$, subcutaneous fat (graded as mild: focal, occasional; moderate: moderately spread; marked: widespread), connective tissue framework (noted as absent: (-) and present: $(+)$ ), and cartilaginous component (noted as absent: $(-)$ and present: $(+))$, were noted together (Table 1, Figures 1-3).

\section{RESULTS}

21 patients comprising 9 cases of hair follicle nevus, 8 accessory tragi patients and 4 trichofolliculoma cases, were recruited to perform a comparison study. There were 10 males and 11 females in the study group. No significant difference was observed between the three study groups in terms of age, gender and histopathological parameters such as density of hair follicles, subcutaneous fat score and presence of connective tissue framework. Cartilaginous component was seen in 8 cases that were diagnosed as accessory tragi, while central cyst and radiating hair follicles were seen in 4 cases which were diagnosed as trichofolliculoma (Figure 4). There was a significant compatibility between accessory tragi clinic and histopathological diagnosis $(p<0.01)$. In addition, 3 of the 4 trichofolliculoma cases had been identified clinically $(p<0.05)$. Unfortunately, none of the hair follicle nevi could be identified clinically; 5 out of 9 cases were misdiagnosed as intradermal nevus and the rest were misdiagnosed as skin tag.

TABLE 1: Documentation of histopathological features, with reference to age, gender, clinical diagnosis and localization of the lesions.

\begin{tabular}{|c|c|c|c|c|c|c|}
\hline \multirow[t]{2}{*}{ Case } & \multirow[t]{2}{*}{ Age/gender } & \multirow[t]{2}{*}{ Localization } & \multirow[t]{2}{*}{ Clinical diagnosis } & \multicolumn{3}{|c|}{ Histopathological features } \\
\hline & & & & HF & SF & CTF \\
\hline 1 & $3 / \mathrm{F}$ & Nose & Intradermal nevus & ++ & Moderate & + \\
\hline 2 & $7 / \mathrm{F}$ & Eyelid & Skin tag & +++ & Mild & - \\
\hline 3 & $14 / \mathrm{M}$ & Cheek & Intradermal nevus & ++ & Marked & + \\
\hline 4 & $8 / \mathrm{M}$ & PAR & Accessory tragus & +++ & Mild & - \\
\hline 5 & $9 / \mathrm{M}$ & PAR & Accessory tragus & + & Marked & + \\
\hline 6 & $2 / \mathrm{F}$ & PAR & Accessory tragus & ++ & Marked & + \\
\hline 7 & $4 / \mathrm{F}$ & PAR & Accessory tragus & +++ & Mild & + \\
\hline 8 & $6 / \mathrm{M}$ & PAR & Accessory tragus & ++ & Moderate & - \\
\hline 9 & $4 / \mathrm{M}$ & PAR & Accessory tragus & +++ & Moderate & - \\
\hline 10 & $32 / \mathrm{F}$ & Eyelid & Skin tag & ++ & Marked & - \\
\hline 11 & $12 / \mathrm{F}$ & Cheek & Intradermal nevus & +++ & Mild & - \\
\hline 12 & $25 / \mathrm{M}$ & Eyebrow & Trichofolliculoma & ++ & Moderate & - \\
\hline 13 & $1 / \mathrm{M}$ & PAR & Accessory tragus & +++ & Mild & + \\
\hline 14 & $5 / \mathrm{F}$ & PAR & Accessory tragus & +++ & Moderate & + \\
\hline 15 & $34 / \mathrm{F}$ & Eyelid & Intradermal nevus & ++ & Marked & - \\
\hline 16 & $53 / \mathrm{M}$ & Scalp & Trichofolliculoma & + & Marked & + \\
\hline 17 & $12 / \mathrm{F}$ & PAR & Accessory tragus & ++ & Mild & - \\
\hline 18 & $67 / \mathrm{M}$ & Scapula & Skin tag & +++ & Marked & + \\
\hline 19 & $11 / \mathrm{F}$ & Nose & Trichofolliculoma & +++ & Mild & - \\
\hline 20 & $4 / \mathrm{M}$ & Eyelid & Intradermal nevus & + & Marked & + \\
\hline 21 & $17 / \mathrm{F}$ & PAR & Accessory tragus & ++ & Moderate & - \\
\hline
\end{tabular}

F: female, M :male, PA R: preauricular region, $\mathrm{HF}$ : hair follicle, SF: subcutaneous fat, CTF: connective tissue framew ork 

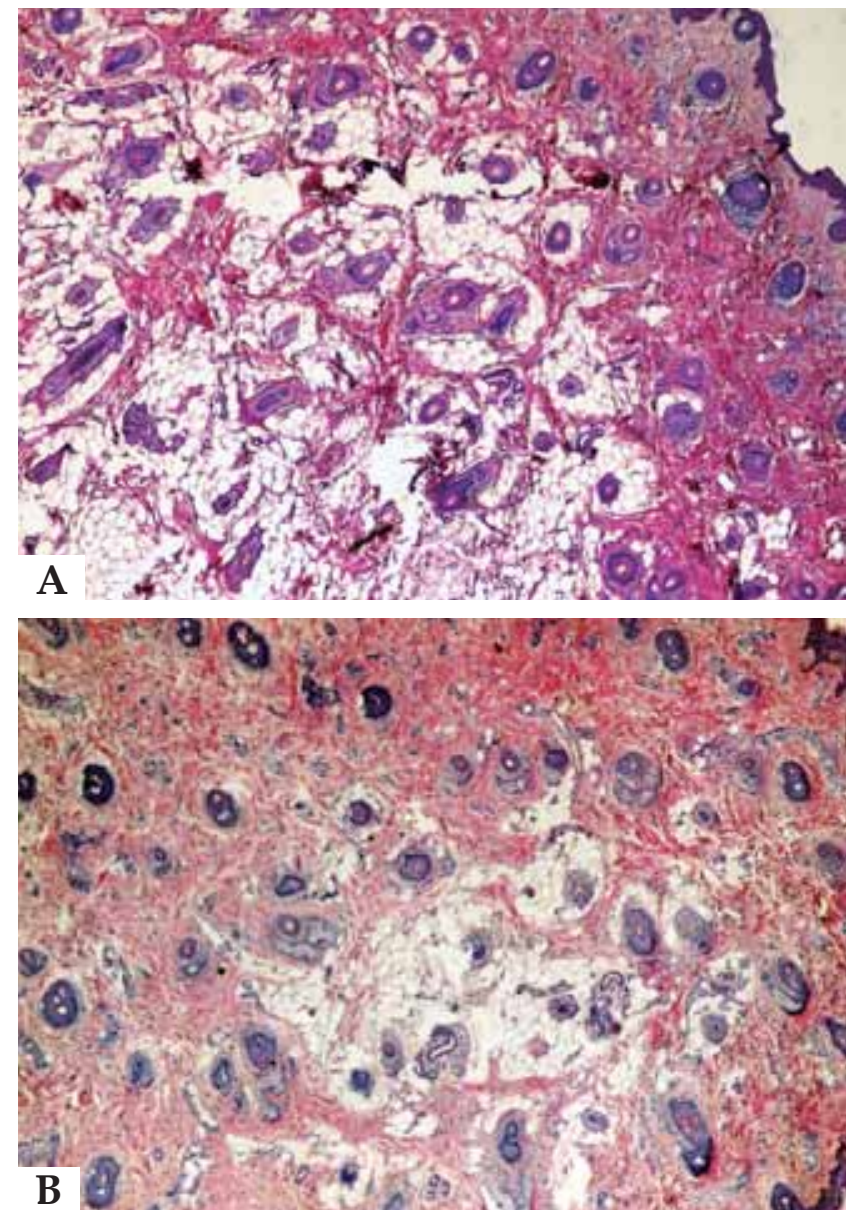

Figure 1: A. Numerous, tiny, mature hair follicles (H\&E x100); B. Mature hair follicles in subcutaneous fat (H\&E x100)

\section{DISAUSSION}

The present study demonstrates that the 3 disorders have an almost identical histopathology. Upon histological examination, hair follicle nevi, accessory tragi and trichofolliculomas have the same histological background, containing varying amounts of numerous, tiny, mature hair follicles, and connective tissue framework in the subcutaneous fat. Fortunately, cartilaginous component proved to be more discriminatory for accessory tragi. Nevertheless, central cyst and radiating hair follicles are related to the diagnosis of trichofolliculoma. Satoh et al. pointed out that a prominent connective tissue framework in subcutaneous fat is the characteristic feature of accessory tragi. ${ }^{10}$ In contrast, Ban et al. explained that a connective tissue framework in subcutaneous fat appears in both hair follicle nevus and accessory auricle, and that the accessory auricle can be differentiated by the presence of abundant, subcutaneous fat. ${ }^{14}$ Further, Germain et al. reported that only the location anterior to the ear was helpful in differentiating the two ${ }^{15}$,

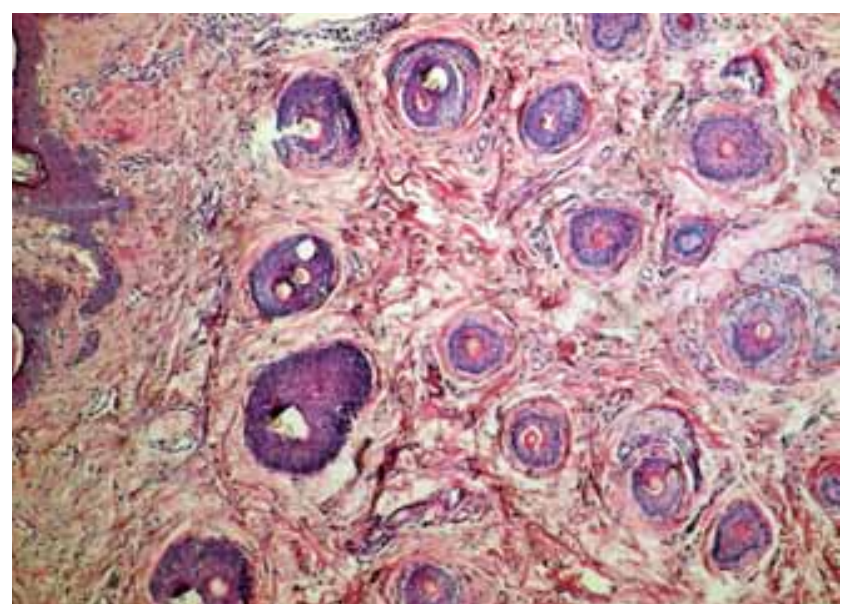

FIGURE 2: Connective tissue framework in subcutaneous fat (H\&E x100)
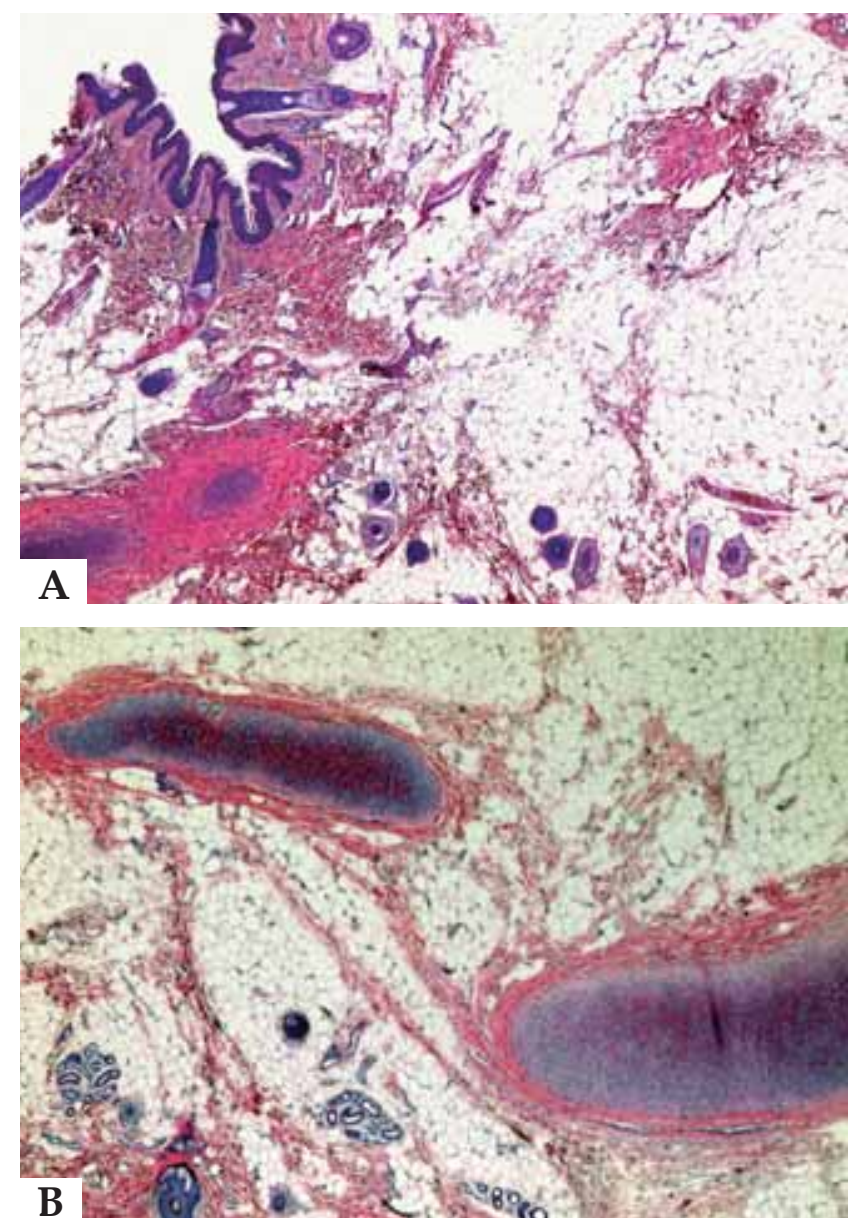

Figure 3: A. Cartilaginous component in adipose tissue (H\&Ex100);

B. Cartilaginous component in adipose tissue (H\&E x200)

while Davis et al. argued that it is difficult to exclude the possibility of hair follicle nevus being an accessory auricle without cartilage, since accessory auricles also have numerous, tiny, mature hair follicles. ${ }^{3}$ 


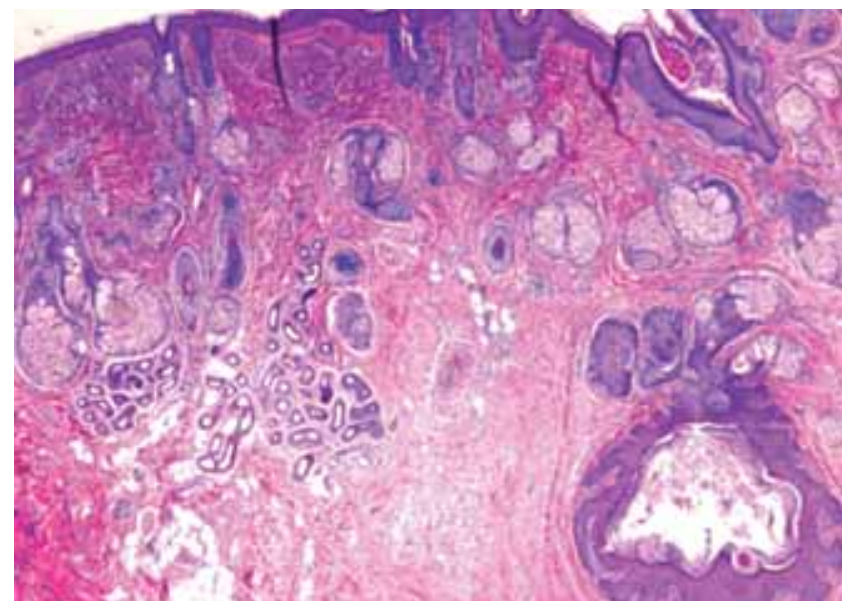

Figure 4: Central cyst with radiating hair follicle (H\&E x100)

In the light of current publications and the results of our study, we can affirm that diagnosing these three lesions can be carried out via clinicopathologic correlation alone.

\section{CONCLUSION}

Although our study included a small number of cases in each group, it is the only report that discusses these three diagnoses. We consider that with the same histopathological morphology, the same entity is named accessory tragi when it is placed around the auricula independently with the cartilage component. It is named trichofolliculoma when it has radiating, small hair follicles and a central cyst. The remaining lesions without these features are referred to as hair follicle nevi.

\footnotetext{
MAILING ADDRESS:

Engin Şenel

$\mathrm{H}$ itit U niversity Faculty of M edicine

D epartment of D ermatology

Bahçelievler M h., 19030

Çorum, Turkey

E-mail: enginsenel@enginsenel.com
}

6. isolated minor ear anomalies. Arch Dis Child Fetal Neonatal Ed. 2006;91:F29-30. with isolated preauricular tags. Pediatrics. 2000;105:E61.

7. Marcondes de Andrade 0 , Jorge SM. An epidemiologic study of preauricular appendages in newborns. Rev Bras Genet 1983;6:761-8.

8. Kliegman RM, Behrman RE, Jenson HB, Stanton BM. Nelson textbook of paediatrics. 18th ed. Philadelphia, PA: Saunders Publishing; 2007.

9. Bianca S, Ingegnosi C, Ettore G. Pre-auricular tags and associated anomalies: considerations for genetic counseling. Genet Couns. 2003;14:321-4.

10. Satoh T, Tokura Y, Katsumata M, Sonoda T, Takigawa M. Histological diagnostic criteria for accessory tragi. J Cutan Pathol. 1990;17:206-10.

11. Asahina A, Mitomi H, Sakurai N, Fujita H. Multiple accessory tragi without cartilage: relationship with hair follicle naevi? Acta Derm Venereol. 2009;89:316-7.

12. Kirihara $Y$, Suenaga $Y$, Take N. Hair follicle nevus with hyperplasia of smooth and striated muscle. J Dermatol. 1990;17:696-700.

13. Hyman AB, Clayman SJ. Hair-follicle nevus; report of a case and a review of the literature concerning this lesion and some related conditions. Arch Dermatol 1957; 93: 678-84.

14. Ban M, Kamiya H, Yamada T, Kitajima Y. Hair follicle nevi and accessory tragi: Variable quantity of adipose tissue in connective tissue framework. Pediatr Dermatol. 1997;14:433-6.

15. Germain M, Smith KJ. Hair follicle nevus in a distribution following Blaschko's lines. J Am Acad Dermatol. 2002;46:S125-7.

How to cite this article: Yuyucu Karabulut Y, Senel E, Karabulut HH, Dolek Y. Three different clinical faces of the same histopathological entity: Hair follicle nevus, trichofolliculoma and accessory tragus. An Bras Dermatol. 2015;90(4):519-22. 